\title{
Calidad del entorno del hogar en niños de zonas rurales: análisis de la línea de base del Servicio de Acompañamiento a Familias (SAF) del Programa Nacional Cuna Más ${ }^{1}$
}

Environmental quality home in rural areas children: analysis of the baseline study of the family support service of the national program "Cuna mas"

Miguel Campos S. ${ }^{2,3}$, José E. Velásquez H. ${ }^{2,3}$, Miguel Ugarelli Z. ${ }^{2,5}$, David Tarazona C. ${ }^{2,4}$, Fernando llanos Z. ${ }^{2,3}$

Ministerio de Desarrollo e Inclusión Social, Dirección General de Seguimiento y Evaluación,Lima - Perú

RECIBIDO 01/06/2016, AcEPTADO 02/08/2016

\begin{abstract}
RESUMEN
Objetivos. Conocer los niveles de calidad del entorno del hogar y explorar sus relaciones con el nivel socioeconómico y la educación de la madre. Materiales y métodos. Estudio cuantitativo-exploratorio realizado durante marzo y agosto de 2013. Se recogió información sobre 5.859 niños menores en el rango de edad de 1 a 24 meses al momento de la entrevista, que conformaban 5.620 hogares en zonas rurales. Asimismo, se recopiló información de 5.723 madres. Se emplearon el Family Care Indicators (FCI) y el Home Observation for Measurement of the Environment (HOME), además de una Encuesta sociodemográfica. Resultados. Los niños de hogares con un mayor nivel de riqueza tienen mayor disponibilidad de materiales de juego; asimismo realizan con más frecuencia actividades en compañía de un adulto y en sus hogares se cuenta con libros para adultos y periódicos. En los hogares con un mayor número de hijos del jefe de hogar, los niños juegan con un menor número de juguetes de diferentes usos y orígenes, y realizan menos actividades con alguna persona mayor. La mayor parte de los padres tuvo prácticas de apego con sus hijos mientras que en relación a la frialdad del hogar, lo más observado fue la prohibición reiterada de hacer algo a alguno de los hijos y dirigirse con gritos hacia alguno de sus hijos. El castigo físico estaría presente en 3 de cada 10 casos. Conclusiones. La evaluación ha permitido establecer una línea de base sobre la cual se diseñará e implementará una estrategia que posibilite una mejora en las prácticas clave de fortalecimiento de crianza en el Programa Nacional Cuna Más.
\end{abstract}

Palabras clave: Calidad del entorno del hogar, FCI, HOME, infancia

1 Este artículo ha sido posible gracias a las actividades realizadas en el marco de la Evaluación del Impacto del Programa Cuna Más. En este sentido, los autores desean expresar su agradecimiento al colectivo de instituciones involucradas en este proceso: Banco Interamericano de Desarrollo (BID), Ministerio de Economía y Finanzas (MEF), Instituto Nacional de Estadística e Informática (INEI), Ministerio de Desarrollo e Inclusión Social (MIDIS) y Programa Nacional Cuna Más.

2 Ministerio de Desarrollo e Inclusión Social, Dirección General de Seguimiento y Evaluación. Lima-Perú.

3 Escuela de Medicina, Escuela de Salud Pública, Universidad Peruana Cayetano Heredia. Lima-Perú.

4 Facultad de Psicología, Universidad Nacional Mayor de San Marcos. Lima-Perú.

5 Departamento Académico de Economía. Facultad de Ciencias Sociales. Pontificia Universidad Católica del Perú. Lima-Perú. 


\begin{abstract}
Objectives. To know the quality standards of the home environment and explore their relationships with socioeconomic status and maternal education. Methods. Quantitative exploratory study done between March and August 2013. We collected data from 5.859 children from 1 to 24 months. We also collected data from 5.723 mothers. We applied the Family Care Indicators (FCI) and the Home Observation for Measurement of the Environment (HOME), and a sociodemographic questionnaire. Results. Children in households with a higher level of wealth have increased availability of play materials; also most frequently performed activities in the company of an adult and in their homes has books for adults and newspapers. In households with more children of the household head, children play with fewer toys of different uses and origins, and perform fewer activities with a grownup. Most parents had practical attachment with their children while in relation to the coldness of the home, as was observed repeated prohibition to do something to one of the children and go with shouts to one of his sons. Physical punishment would be present in 3 of 10 cases. Conclusions. The evaluation has established a baseline on which will be designed and implemented a strategy that enables an improvement in key breeding practices to strengthen the National Program "Cuna Mas”.
\end{abstract}

Keywords: Enviromental quality home, FCI, HOME, childhood.

\title{
INTRODUCCIÓN
}

Los primeros años de vida se consideran la ventana de oportunidad más importante para sentar las bases del desarrollo futuro de una persona. El Desarrollo Infantil Temprano (DIT) es un proceso progresivo, multidimensional, integral y oportuno que se traduce en la construcción de capacidades cada vez más complejas, que permiten al niño y la niña ser competentes a partir de sus potencialidades para lograr una mayor autonomía en interacción con su entorno en pleno ejercicio de sus derechos ${ }^{6}$.

El desarrollo en la infancia temprana se ve afectado por el entorno y las experiencias que los niños acumulan desde la gestación hasta sus primeros años, siendo a su vez la etapa de mayor vulnerabilidad, pues los efectos de un desarrollo inadecuado pueden ser irreversibles (Shonkoff \& Phillips, 2000). Las influencias interactivas de los genes y las experiencias en edades tempranas dan forma a la arquitectura del cerebro en desarrollo, y el ingrediente activo en ese proceso es la naturaleza de las relaciones de los niños con sus padres y otros adultos en el hogar o la comunidad (Center on the Developing Child at Harvard University, 2007). La pobre estimulación en el hogar es uno de los principales factores que afectan el desarrollo de los niños que viven en situación de pobreza (Hammadami y cols, 2010).

Las mediciones realizadas para evaluar la influencia del hogar en los niños han mostrado una correlación positiva importante con las medidas de desarrollo cognitivo; estas correlaciones son más fuertes luego de los dos años de edad y algo menores en el caso de entre seis y doce meses (Totsika \& Sylva, 2004);

6 PERÚ: Lineamientos para la Gestión Articulada Intersectorial e Intergubernamental orientada a Promover el Desarrollo Infantil Temprano "Primero la Infancia". Resolución Suprema N 413-2013-PCM. 
también se ha hallado que las madres que mostraron una mayor susceptibilidad y sensibilidad (responsiveness) fueron capaces de establecer un mayor apego emocional con sus hijos (Totsika \& Sylva, 2004). Un estudio ha informado una relación moderada entre el HOME y escalas de medición del Trastorno por Déficit de Atención e Hiperactividad (TDAH) (Tofail y cols, 2013; Mulligan y cols, 2013). El HOME ha sido empleado exitosamente en la medición pre y post de programas de intervención con familias, especialmente en programas de salud y con niños en situación de riesgo (Totsika \& Sylva, 2004); con relación a esto último se ha hallado diferencias significativas en los puntajes obtenidos en el HOME entre familias pobres y familias no pobres, especialmente en la escala «aprendizaje» (Totsika \& Sylva, 2004).

En un estudio con niños pobreza de zonas rurales de Bangladesh, se halló una correlación positiva entre el puntaje alcanzado en el Family Care Indicators (FCI), otra prueba utilizada para medir calidad en el hogar, y el índice de masa corporal materno con el desarrollo cognitivo de los niños (medido con la Escala Bayley); en este mismo estudio, se reportó que los niños que recibieron tratamiento (estimulación) alcanzaron mayores puntajes en FCI que los que no lo recibieron, tanto en línea de base como en la evaluación final (Tofail y cols, 2013).

El desarrollo infantil temprano se ve influenciado por factores relativos a su entorno cercano -clima familiar, estilo de vida, pobreza del hogar. El presente artículo expone los resultados del estudio de línea de base del Servicio de Acompañamiento a Familias (SAF) del PNCM, el cual tuvo como objetivo la evaluación de los niveles de calidad del entorno del hogar en niños residentes en zonas rurales, explorando si existe algún nivel de asociación con el índice de riqueza de las familias y la educación de la madre.

\section{MATERIALES Y MÉTODOS}

\section{Tipo y diseño}

Estudio de tipo cuantitativo-exploratorio y de diseño experimental (aunque en este reporte se presentan los resultados en modo descriptivo), la asignación de observaciones se realizó de manera aleatoria a nivel de conglomerados. Las encuestas se realizaron a domicilio.

\section{Población y muestra}

5784 viviendas con al menos un niño de 1 a 24 meses ubicadaos en hogares de 12 departamentos, 180 distritos y 360 centros poblados. Además, 5723 madres y 3487 hermanos; el inmediatamente mayor al niño objeto del estudio que tenga entre 3 y 18 años. Los hogares están ubicados en zonas predominantemente rurales con tasas de pobreza mayores a 50\% y tasas de desnutrición de al menos 30\%.

Para determinar el tamaño de la muestra, tomando en cuenta que el presente estudio servirá como insumo para la posterior evaluación del programa, se consideró una 
correlación intragrupos (ICC) de 0.05, calculada con datos de la Encuesta Niños del Milenio (Young Lives). Esta correlación es similar a la encontrada en estudios similares en países como Colombia (Attanasio y cols, 2013) y Ecuador (con un ICC de 0.10 usando datos longitudinales del estudio Cerrando Brechas). Además se consideró un nivel de significancia de $5 \%$ y un poder de $80 \%$.

Dada la capacidad de expansión inicial del Programa, se trabajó con una muestra de 180 distritos, de los cuales 120 deberían contar con el servicio desde inicios de 2013 y 60 podrían incorporarse luego del levantamiento de la línea de seguimiento.

Por el diseño, la muestra del estudio no es representativa de la población nacional de niños menores de 36 meses, tampoco tiene inferencia distrital ni provincial por lo siguiente: i) la intervención está focalizada en 646 distritos, ii) algunas regiones y distritos han sido excluidos del marco de la evaluación porque son considerados de atención priorizada y su intervención podría no ajustarse al cronograma de la evaluación, y iii) la muestra solo considera a los dos centros poblados rurales con la mayor cantidad de niños entre 0 y 24 meses. En este sentido, la muestra ha sido seleccionada para producir validez interna de los resultados, en el sentido de producir comparabilidad entre los grupos de tratamiento y control, con lo cual la validez externa del estudio es limitada.

\section{Variables e indicadores}

Tabla 1. Variables e indicadores incluidos en el análisis

\begin{tabular}{|c|c|}
\hline Variables & Indicador \\
\hline \multicolumn{2}{|c|}{ Variables sobre calidad del entorno del hogar } \\
\hline \multirow{5}{*}{$\begin{array}{l}\text { Calidad del ambiente en } \\
\text { el hogar - Interacciones }\end{array}$} & Puntaje en la escala de calidad del ambiente del hogar (HOME) \\
\hline & Adultos que leen libros, cuentan cuentos o les cantan a los niños $\left(\mathrm{N}^{\circ}\right.$ de días $)$ \\
\hline & Adultos que utilizan juguetes para jugar con los niños $\left(\mathrm{N}^{\circ}\right.$ de días $)$ \\
\hline & Adultos que salen a pasear con los niños ( $\mathrm{N}^{\circ}$ de días) \\
\hline & Adultos que hacen dibujar o pintar a los niños $\left(\mathrm{N}^{\circ}\right.$ de días $)$ \\
\hline \multirow{13}{*}{$\begin{array}{l}\text { Disponibilidad de } \\
\text { espacios físicos y } \\
\text { materiales en el hogar } \\
\text { que favorecen el } \\
\text { desarrollo infantil }\end{array}$} & Adultos que juegan a nombrar/contar objetos o colores con los niños $\left(\mathrm{N}^{\circ}\right.$ de días) \\
\hline & Madres que habilitan un espacio de juego adecuado para sus niños \\
\hline & Niños que disponen de un espacio para guardar sus juguetes \\
\hline & Número de libros, revistas y/o periódicos en el hogar \\
\hline & Número de juguetes hechos en casa \\
\hline & Número de juguetes comprados/fabricados \\
\hline & Número de juguetes para armar o construir \\
\hline & Número de juguetes para pintar o escribir \\
\hline & Número de juguetes que requieren movimiento físico \\
\hline & Número de juguetes para el juego de roles \\
\hline & Número de libros infantiles de cuentos y/o con imágenes para colorear \\
\hline & Número de juguetes para aprender formas y colores \\
\hline & Número de juguetes que producen música o imágenes audiovisuales \\
\hline \multicolumn{2}{|c|}{ Variables de control/comparación } \\
\hline Rangos de edad & $\begin{array}{l}\text { Edad cronológica ordenada en los siguientes rangos de edad (en meses): 0-6, } \\
7-12,13-18,19-24\end{array}$ \\
\hline Nivel socioeconómico & Índice de riqueza del hogar \\
\hline Educación de la madre & Años de escolaridad de la madre \\
\hline
\end{tabular}




\section{Instrumentos}

- Family Care Indicators (FCI): Mide la calidad del entorno del hogar de niños pequeños. Fue desarrollado por UNICEF a base de ítems de diferentes fuentes, incluyendo el HOME (Frongillo, 2003) y ha sido validado contra el Home Observation for Measurement of the Environment (HOME) en Bangladesh (Hammadami y cols, 2010).

- Home Observation for Measurement of the Environment (HOME): Permite evaluar la calidad del ambiente del hogar. Se trabajó con un subconjunto de los ítems de las subescalas de responsividad y aceptación relacionados con la calidez y/o la dureza (harshness) de las interacciones entre padres e hijos observadas durante la entrevista.

- Encuesta Sociodemográfica: Permitió medir variables de control referidas a las condiciones iniciales de salud y estado nutricional de los niños, características de las madres (gestación y parto, depresión, nivel educativo y una proxy de habilidad intelectual) y condiciones socioeconómicas del hogar.

\section{Recolección de datos}

El trabajo de campo estuvo a cargo de personal del Instituto Nacional de Estadística e Informática (INEI). Se llevaron a cabo dos pruebas piloto para evaluar el diseño y estructura de la encuesta, el fraseo de las preguntas, la logística del operativo y establecer el tiempo promedio de aplicación (1h $25 \mathrm{~min}$ ). Previo al operativo de campo, se realizó la capacitación de encuestadores, durante 19 días, mediante sesiones teóricas y prácticas (entrevistas en aula con madres y niños). Se contó con 77 aplicadores, 45 supervisores locales y 12 coordinadores departamentales.

\section{Análisis estadístico}

El procesamiento y posterior análisis fueron realizados con el paquete estadístico STATA 13. Los hogares fueron clasificados según su nivel de riqueza mediante un índice construido ad-hoc en el que se consideraron las variables referentes a la disponibilidad de activos y servicios, y los materiales de la vivienda. Sin embargo, no fueron incluidas en el índice todas las variables disponibles. El primer criterio para la inclusión de las variables fue su variabilidad, descartándose los bienes, servicios o materiales que estaban presentes en menos del $10 \%$ de los hogares de la muestra. El segundo criterio fue que las variables tengan una contribución significativa al componente. El índice resume información sobre la tenencia de activos (como equipo de sonido, televisor, refrigerador, cocina a gas, entre otros), el material del piso y la disponibilidad de electricidad, agua y servicios higiénicos. Se divide a los hogares en cuartiles de riqueza, y se comparan los hogares en el cuartil 1 (más pobre) y en el cuartil 4 (menos pobre), utilizando regresiones no paramétricas (regresión Fan). 


\section{Aspectos éticos}

En cada hogar seleccionado hubo explicación de la encuesta a realizar y se solicitó el consentimiento escrito respectivo. Además, la confidencialidad fue protegida en todo momento, separando la información personal de aquella necesaria para el análisis.

\section{RESULTADOS}

\section{Family Care Indicators (FCI)}

Se recogió información sobre las características de los juguetes según su uso o en función de su origen (comprados u objetos del hogar). También se preguntó sobre la realización y frecuencia de actividades de juego de los niños con alguna persona mayor de 15 años y la disponibilidad de libros (excluyendo libros para niños), revistas o periódicos.

Las figuras del 1 al 5 resumen las diferencias entre los niños del cuartil 1 y 4 .

Figura 1. Disponibilidad de materiales de juego clasificados según su uso por cuartiles de riqueza

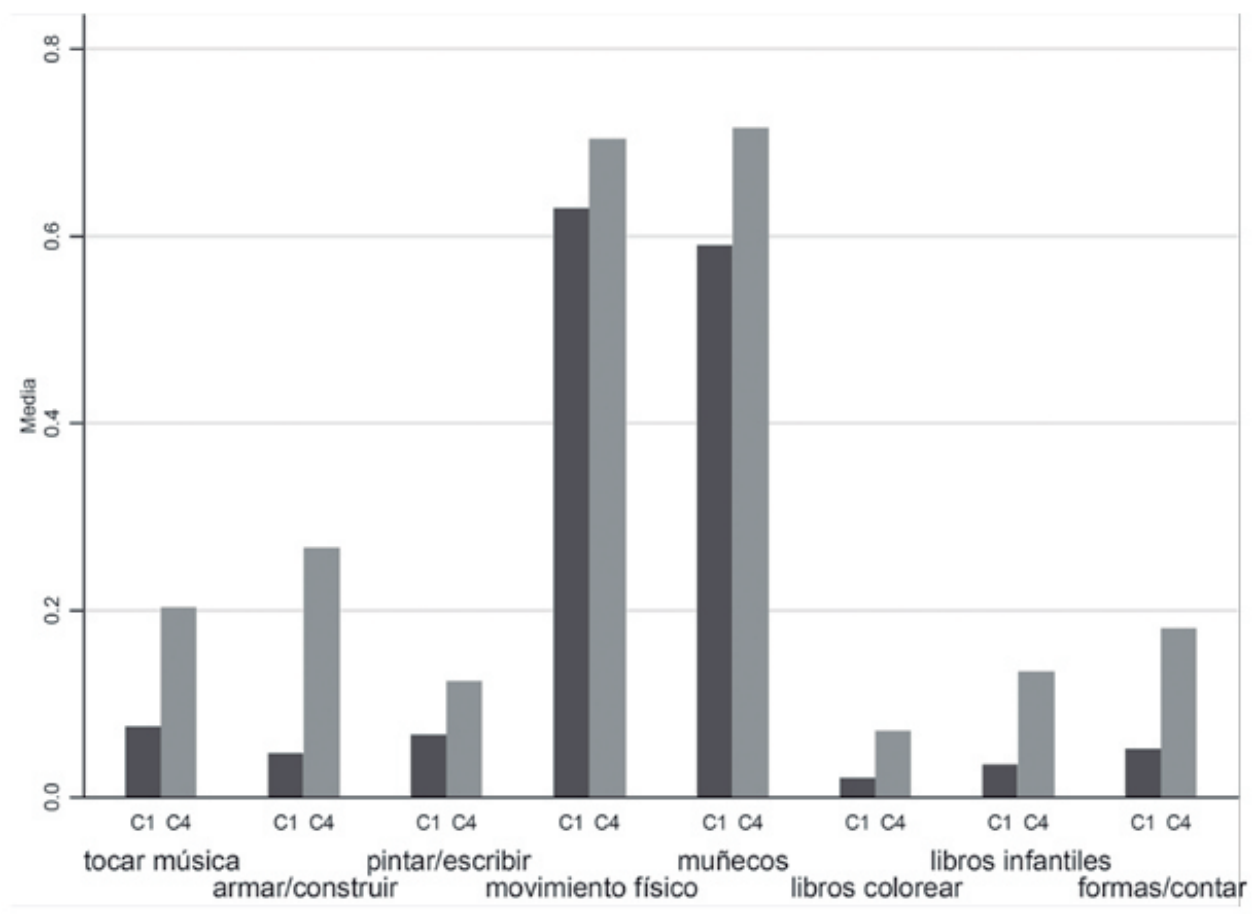

Los diferentes materiales de juego, clasificados según su uso, están disponibles para un mayor porcentaje de niños en los hogares del cuartil 4 en relación a los niños de hogares en el cuartil 1 , y en particular se destacan las diferencias en la disponibilidad de juguetes para tocar música $(8 \%$ de los niños del cuartil 1 vs $20 \%$ del cuartil 4), juguetes para armar o construir (5\% vs $27 \%$ ) y juguetes para aprender formas o contar (5\% vs $18 \%)$. 
Figura 2. Disponibilidad de materiales de juego clasificados según su origen por cuartiles de riqueza

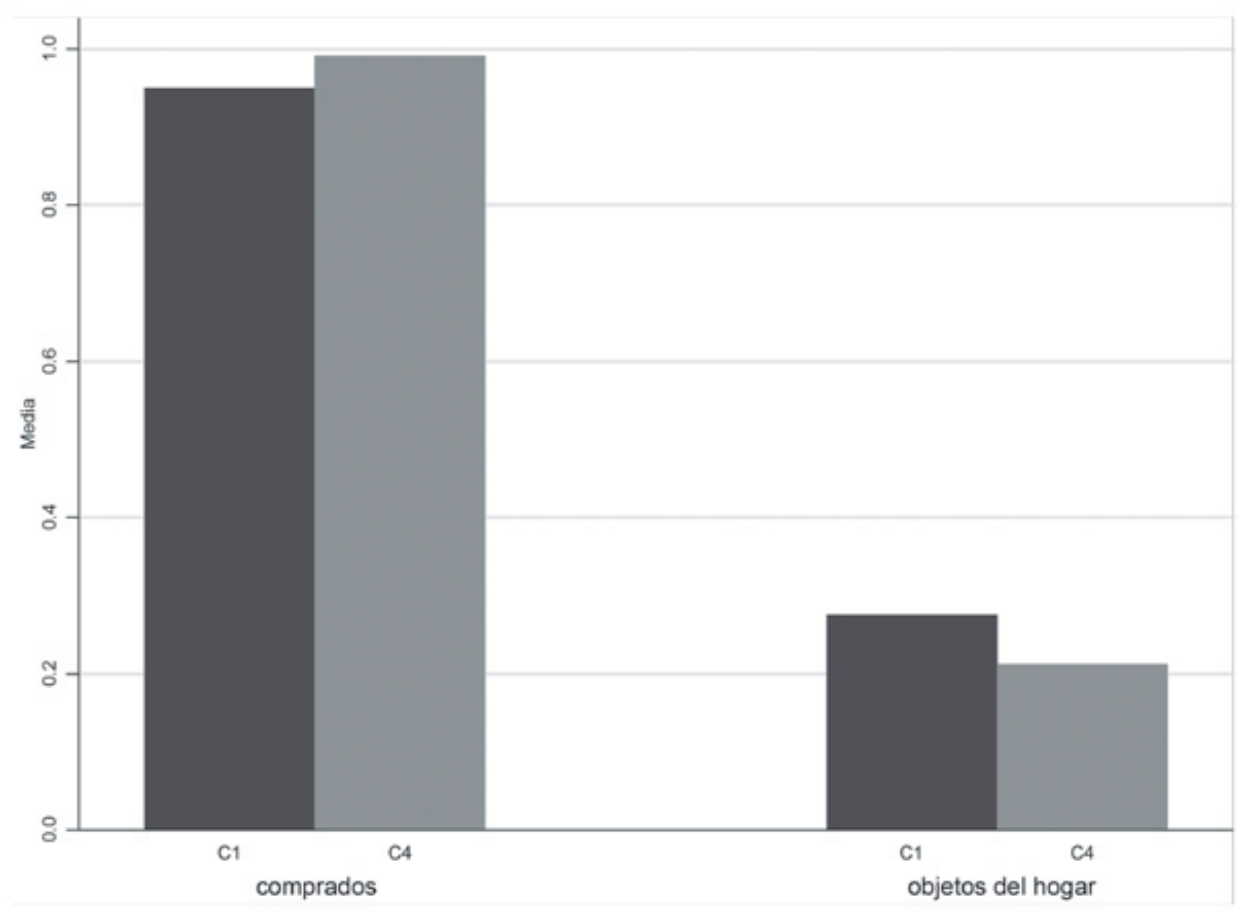

En relación al origen de los juguetes, si bien la mayoría de los niños en los dos cuartiles analizados disponen de juguetes comprados, el porcentaje de niños es levemente superior en el cuartil 4. Mientras que los objetos del hogar son utilizados en mayor medida por niños del cuartil 1.

Figura 3. Realización de actividades de juego junto a una persona mayor de 15 años por cuartiles de riqueza

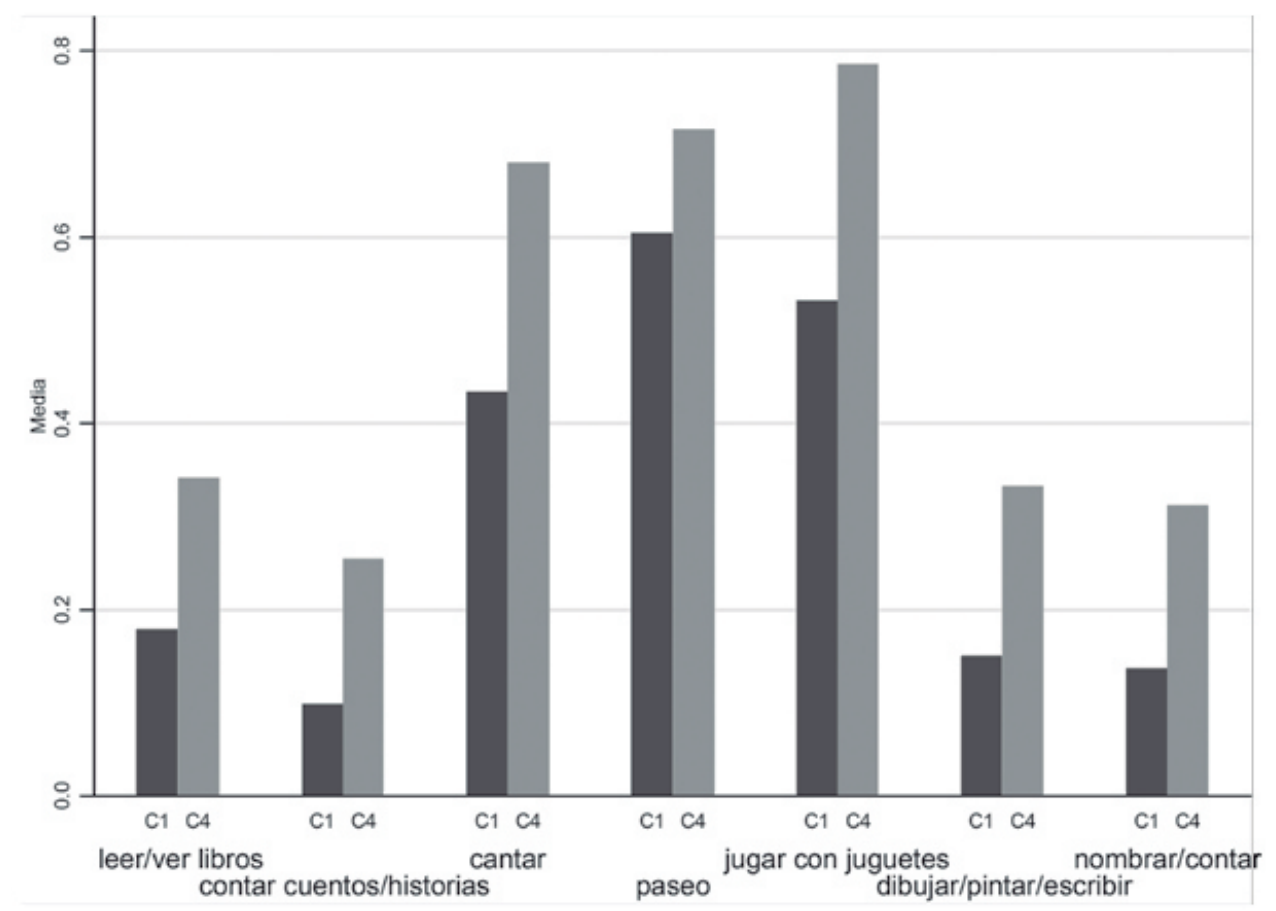


Durante la semana previa a la entrevista, los niños del cuartil 4 realizaron en promedio 3 actividades diferentes junto a un adulto; en cambio, los niños de hogares en el cuartil 1 participaron de 2 actividades distintas en compañía de un adulto. El porcentaje de niños que realizó alguna de las diferentes actividades es mayor para aquellos que viven en hogares del cuartil 4 en relación a los que pertenecen a hogares del cuartil 1 .

Figura 4. Libros y periódicos en el hogar por cuartiles de riqueza

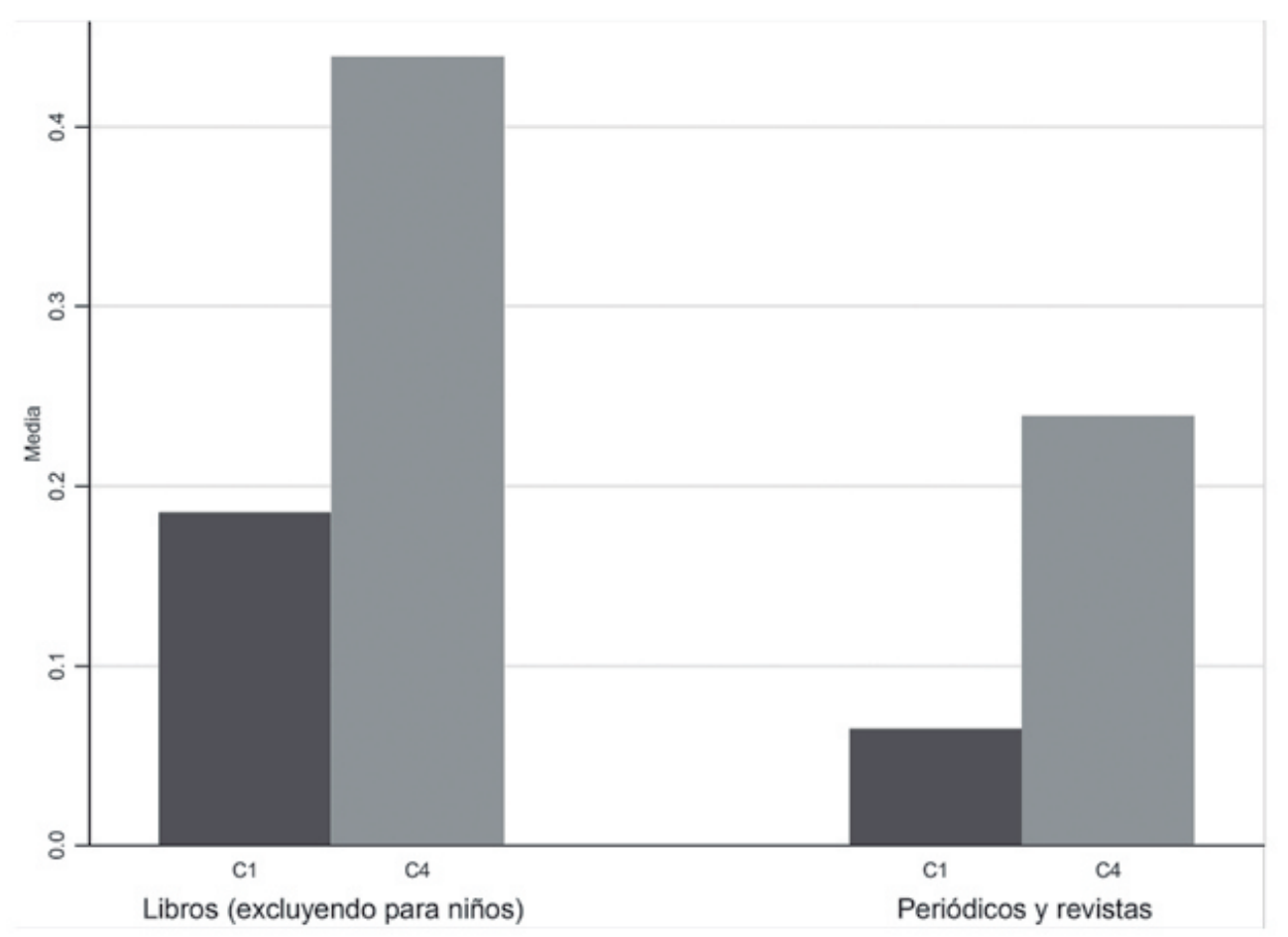

El porcentaje de los hogares en el cuartil 4 que tiene libros para adultos y periódicos (44\% y $24 \%$, respectivamente) es mayor al porcentaje entre los del cuartil $1(19 \%$ y $6 \%$ ).

Las correlaciones entre las subescalas del FCI y el número de hijos del jefe de hogar son significativas y de signo negativo: en los hogares con un mayor número de hijos del jefe de hogar, los niños juegan con un menor número de juguetes de diferentes usos y orígenes, y realizan menos actividades con alguna persona mayor.

\section{Home Observation for Measurement of the Environment (HOME)}

En la siguiente tabla se presenta el análisis de regresión lineal buscando conocer la relación entre los resultados de las dimensiones del HOME y las variables edad del niño, riqueza del hogar y educación de la madre. 
Tabla 1. HOME - Análisis de regresión lineal para edad, riqueza y educación de la madre ${ }^{7}$

\begin{tabular}{lc}
\hline \multicolumn{2}{c}{ Home } \\
\hline Edad en meses al cuadrado & 0,0002 \\
Índice de Riqueza & $-0,2334$ \\
Años de educación de la madre & $-0,1134$ \\
_cons (Constante) & 3,2434 \\
& \\
R-cuadrado & 0,0722 \\
R-cuadrado ajustado & 0,0719 \\
\hline
\end{tabular}

En general, se puede afirmar que el poder explicativo del modelo es limitado en la medida en que el valor R-cuadrado es bajo.

También se recogió un subconjunto de los ítems de las subescalas de responsividad y de aceptación de la escala HOME, relacionados con la calidez y/o la dureza (harshness) de las interacciones entre padres e hijos observadas durante la entrevista.

Un puntaje mayor quiere decir que el ambiente del hogar es más "duro" o "frío". Por ejemplo, un hogar es "duro" si la madre o su pareja gritan, regañan o pegan a algunos de los niños del hogar durante la entrevista, si expresan hostilidad hacia ellos, o si les prohíben hacer algo reiteradamente. Mientras que un hogar es "frío" cuando las interacciones entre adultos y niños no demuestran calidez: los adultos no expresan palabras de afecto hacia los niños, no les responden afectuosamente, no alaban a sus hijos, o al hablar sobre sus hijos transmiten sentimientos negativos. Los hogares observados, en promedio, obtienen 0.55 puntos sobre un total de 5 puntos en términos de la "dureza" del hogar. Con respecto a cuán "frío" es el hogar, el puntaje obtenido es de 2 puntos, en una escala que va del 0 al $6^{8}$.

Se observó que, durante la entrevista, más del 60\% de los padres o informantes enseñó a alguno de sus hijos algo sobre un objeto o persona (70\%), transmitió sentimientos positivos al hablar de sus hijos (70\%), acarició o besó a sus hijos (70\%), dirigió palabras o sonidos de afecto de forma espontánea a sus hijos por lo menos en dos ocasiones (67\%), respondió verbalmente a los sonidos o palabras de afecto de sus hijos (64\%), y alabó espontáneamente a alguno de sus hijos por lo menos en dos ocasiones (57\%). En relación a la frialdad del hogar, lo más observado fue la prohibición reiterada de hacer algo a alguno de los hijos (16\%) y dirigirse con gritos hacia alguno de sus hijos (15\%). En el 3\% de los casos se observó que la informante o su pareja le pegaron a alguno de sus hijos durante la entrevista, y $9 \%$ expresó fastidio hacia alguno de ellos.

En el $77 \%$ de los casos, las madres reportan que en general recurren a algún tipo de corrección para desincentivar comportamientos no apropiados. De entre las alternativas de respuesta ofrecidas, entre las que no estaba golpear al niño ni la

7 El factor de expansión utilizado es "fact_cap_500_600_600a_900" relacionado con el módulo del ASQ (módulo 600).

8 En promedio, en la Encuesta Longitudinal de Ecuador (1,945 hogares, datos correspondientes al tercer seguimiento en 2011) tienen un puntaje menor en términos de la dureza del hogar (0.32 puntos), y mayor en términos de la frialdad (3.21 puntos). 
agresión verbal, las madres reportan de forma casi exclusiva el mantener una conversación con el niño ( $72 \%$ de los casos).

Adicionalmente, se preguntó acerca la forma de corrección usada ante comportamientos no adecuados durante la semana previa a la entrevista. El reporte materno indica que 3 de cada 10 niños recibieron gritos, regaños o insultos por parte de sus madres y un $17 \%$ recibieron pellizcos, tirones de pelo, o golpes con la mano.

En relación con el reconocimiento de buenos comportamientos, las madres de más de la mitad de los niños (56\%) reporta que durante la semana previa a la entrevista abrazó, consintió o fue cariñosa con el niño cuando este hizo algo bueno o que le gustó; alrededor de la mitad de la madres (49\%) se alegró y se rio junto a su niño, y un menor número de madres (18\%) felicitó verbalmente o aplaudió al niño.

Menos de la mitad de los niños (44\%) se queda en el hogar sin la presencia de la madre (datos no reportados en la Tabla 25). En estos casos, los niños quedan con mayor frecuencia a cargo de una persona de 10 años o más: el $26 \%$ del total de niños en el grupo de control es cuidado por otro miembro del hogar, y $8 \%$ por una persona de otro hogar. Solo el $6 \%$ de los niños queda al cuidado del padre ante la ausencia temporal de la madre en el hogar.

Tabla 1. Correlaciones entre variables

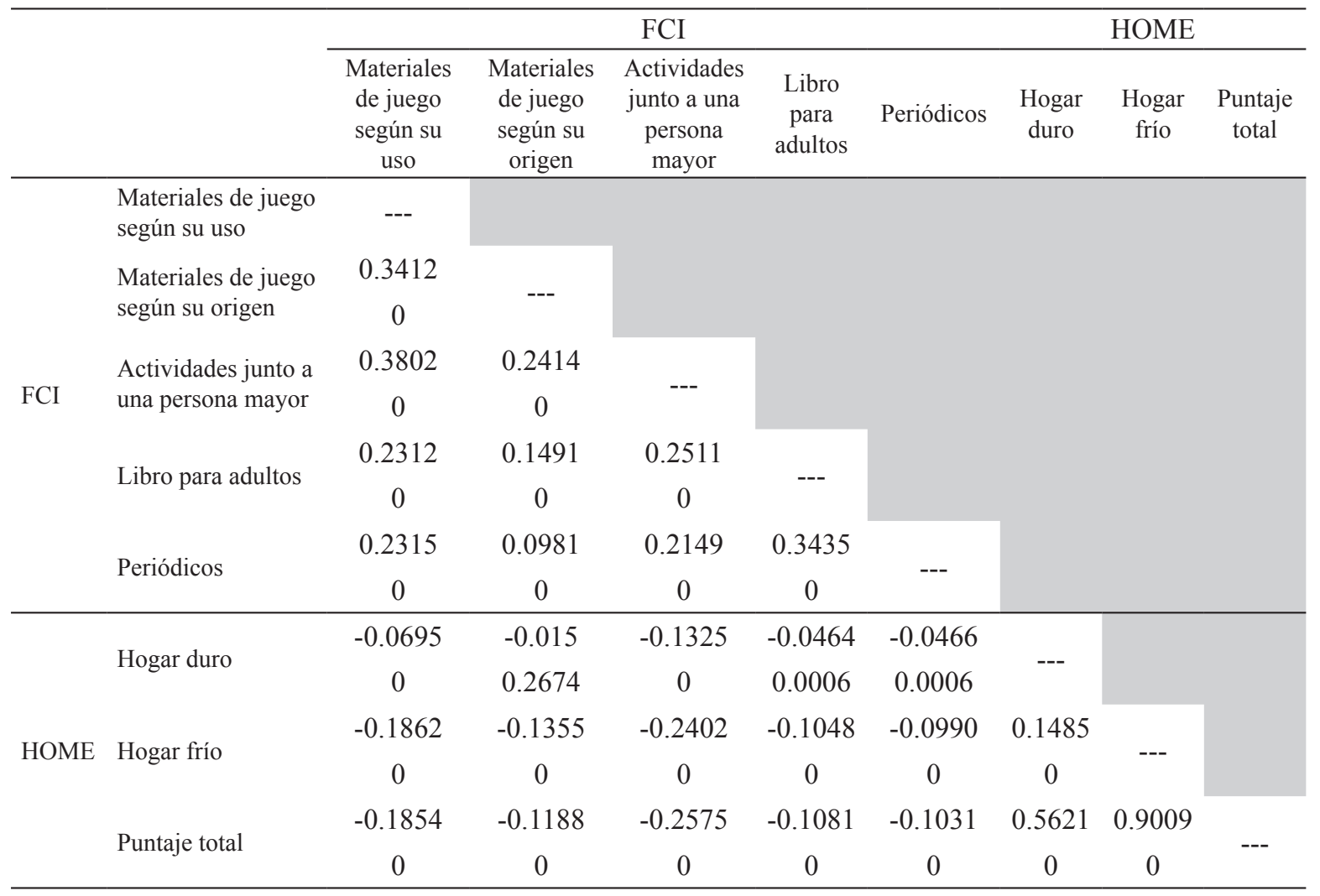

$* \mathrm{p}<0.01$ 


\section{DISCUSIÓN}

En el presente estudio se ha explorado si existe algún nivel de asociación entre la calidad del entorno en el hogar con el nivel socioeconómico y la educación de la madre. Las mediciones se han realizado con los cuestionarios Family Care Indicators (FCI) y Home Observation for Measurement of the Environment (HOME). Adicionalmente se aplicó una encuesta sociodemográfica. En total, han participado 5859 niños y niñas con edades entre 1 y 24 meses al momento de la entrevista y 5723 madres o cuidadores principales.

En relación a los resultados alcanzados con el Family Care Indicators (FCI), los niños de hogares con un mayor nivel de riqueza tienen mayor disponibilidad de materiales de juego, especialmente juguetes para tocar música, juguetes para armar o construir y juguetes para aprender formas o contar; asimismo, realizan con más frecuencia actividades en compañía de un adulto y en sus hogares se cuenta con libros para adultos y periódicos. Según los datos recogidos, otro factor que afecta la calidad del ambiente es el número de hijos: en los hogares con un mayor número de hijos del jefe de hogar, los niños juegan con un menor número de juguetes de diferentes usos y orígenes, y realizan menos actividades con alguna persona mayor. El origen de la mayor parte de los juguetes es comprado, tanto en niños de cuartil 1 como del cuartil 4. Resultados similares han sido reportados en estudios previos (Hammadami y cols, 2010; Tofail y cols, 2013; Attanasio y cols, 2013).

Con respecto al Home Observation for Measurement of the Environment (HOME), se observó un conjunto de interacciones positivas, como que la mayor parte de los padres o informantes enseñó a alguno de sus hijos algo sobre un objeto o persona, transmitió sentimientos positivos al hablar de sus hijos, acarició o besó a sus hijos, dirigió palabras o sonidos de afecto de forma espontánea a sus hijos por lo menos en dos ocasiones, respondió verbalmente a los sonidos o palabras de afecto de sus hijos, y alabó espontáneamente a alguno de sus hijos por lo menos en dos ocasiones (57\%); en relación a la frialdad del hogar, lo más observado fue la prohibición reiterada de hacer algo a alguno de los hijos y dirigirse con gritos hacia alguno de sus hijos. Resultados similares han sido reportados en estudios previos (Totsika \& Sylva, 2004)

Finalmente, cabe destacar que la mayor parte de las madres reporta que en general recurren a algún tipo de corrección para desincentivar comportamientos no apropiados. Es frecuente la práctica de mantener una conversación con el niño. El castigo físico estaría presente en 3 de cada 10 casos. El entorno familiar rural tiene características muy particulares que permiten la coexistencia de intercambios afectivos entre padres e hijos llenos de cariño y ternura, de un entorno lúdico lleno de cánticos y juegos de roles junto a severas medidas disciplinarias (Rosemberg \& Amado, 2007). Esta situación explicaría en parte los resultados obtenidos. 


\section{REFERENCIAS BIBLIOGRÁFICAS}

Attanasio, O.; Grantham-McGregor, S.M.; Fernández, C.; Fitzsimons, E.; RubioCodina, M. \& Meghir, C. (2013). Enriching the home environment of lowincome families in Colombia: A strategy to promote child development at scale. Early Childhood Matters. Bernard Van Leer Foundation.

Bradley, R. H. (1993). Children's Home Environments, Health, Behavior, and Intervention Efforts: A Review Using the HOME Inventory as a Marker Measure. Genetic, Social, and General Psychology Monographs(119), 437490.

Center on the Developing Child at Harvard University. (2007). A science based framework for early childhood policy: Using evidence to improve outcomes in learning, behavior and health for vulnerable children. USA: CDCHHU.

Frongillo, E. S. (2003). UNICEF psychosocial care indicators project. Final report to UNICEF, Cornell University.

Hamadami, J. D., Tofail, F., Hilaly, A., Huda, S. N., Engle, P., \& GranthamMcGregor, S. M. (2010). Use of family care indicators and their relationship with child development in Bangladesh. Journal of Health, Population and Nutrition, 28(1), 23-33.

Mulligan, A; Anney, R; Butler, L.; O’Regan, M; Richardson, T.; Tulewicz, E. M.; Fitzgerald, M. \& Gill, M. (2013). Home environment: association with hyperactivity/impulsivity in children with ADHD and their non-ADHD siblings. Child Care Health Development; 39(2): 202-212. doi:10.1111/ j.1365-2214.2011.01345.x.

Rosemberg, C. R. \& Amado, B. (2007). Aprender haciendo con otros. Un estudio del aprendizaje infantil en el marco de los sistemas de actividad de comunidades rurales. Revista de Investigación en Psicología, Vol. 10, N. . 2 , pp. 9-27.

Shonkoff, J., \& Phillips, D. (2000). From neurons to neighborhoods: The science of early childhood development. USA: Institute of Medicine.

Tofail, F., Hamadami, J. D., Mehrin, F., Ridout, D. A., \& Huda, S. N.-M. (2013). Psychosocial Stimulation Benefits Development in Nonanemic Children but Not in Anemic, Iron-Deficient Children. The Journal of Nutrition. doi:10.3945/jn.112.160473.

Totsika, V., \& Sylva, K. (2004). The Home Observation for Measurement on the Environment Revisited. Child and Adolescent Mental Health, 9(1), 25-35. 